\title{
Research on Current Situation and Problems of Sail-Assisted Ship
}

\author{
Zijian Chen ${ }^{1, a}$, Fan Pan ${ }^{1, b}$, Zhentao Wang ${ }^{1, c}$ \\ ${ }^{1}$ The Institute of Military Transportation, Tianjin 300161, China

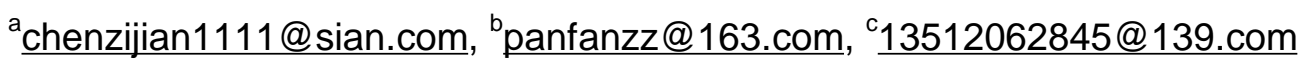

\begin{abstract}
Keywords: Ship; Energy; Sail-Assisted; Energy Conservation
Abstract. With the energy crisis and the further optimization of EEDI for new ships from International Maritime Organization, the Sail-Assisted becomes the developing direction of ship in the future. Aiming at the wide application prospect of the Sail-Assisted in the ship, introduces the application of Sail-Assisted technology in the field of ship, analysis the existing problems, this paper puts forward and prospect the future research direction.
\end{abstract}

\section{Introduction}

The progress of science and technology makes the social wealth extremely rich. However on fossil fuels for energy of modern industry development, but it makes human survival environment worsening, the greenhouse effect and the atmospheric ozone layer destruction is a growing threat to human survival. Also due to fossil fuel resources are limited, people have felt the danger of energy depletion, coupled with the international community on emissions requirements increasingly strict, the development of new energy sources is urgent. So humans have to explore new sources of energy to replace fossil fuels. Wind energy is a typical kind of clean and renewable energy, its abundant, convenient to access attracted widespread attention. The Sail-Assisted rely on wind energy to assist the sailing ship, effectively reduce the ship fuel consumption and exhaust emissions, become a bright spot in the new energy research ship.

\section{Analysis on the principle of the Sail-Assisted}

The thrust produced by the modern sail is very similar to that of the aircraft's wing. When the sail with the wind into a angle, the flow rate of air on the leeward side of the sail is greater than the windward, and the streamline on the leeward is denser than the windward. According to Bernoulli's law, where the fluid flow rate is large, the pressure generated by the fluid is small, the fluid flow rate is small, and the pressure generated by the fluid is large. Therefore, the air flow rate on the leeward is large, and the air pressure generated by the air is small; on the windward, the air flow rate is small, and the pressure of the air is large, so that a pressure difference is generated on the two side of the sail. The product of the pressure difference and the projected area of sail is the air in the sail from windward to leeward of the total pressure.

Assuming the actual wind speed at sea is $V_{C}$, the ship speed is $V_{X}$, the apparent airflow speed on the sail is $V$, which is the vector synthesis of actual wind speed and ship speed. Under the action of the apparent airflow speed, the sail generates a lift $L$ that is perpendicular to the apparent airflow speed and a resistance $D$ that along the apparent airflow speed. When the apparent airflow speed $V$ flows to sail with wind direction angle $\theta$, suppose at this time the sail angle is $\varphi$, the included angle between the apparent airflow speed $\mathrm{V}$ and sail string is $\alpha$.

Decompose the lift $L$ and the resistance $D$ into two component, the one is along the direction of the ship, the other is perpendicular to the direction of the ship, then we can take the Sail assisted thrust force $F_{X}$ and the transverse force $F_{Y}$ of the sail as follows:

$$
\begin{aligned}
F_{X} & =L \sin \theta-D \cos \theta \\
F_{Y} & =L \sin \theta+D \cos \theta
\end{aligned}
$$


Expressed by Dimensionless coefficient:

$$
\begin{aligned}
& C_{X}=C_{L} \sin \theta-C_{D} \cos \theta \\
& C_{Y}=C_{L} \sin \theta+C_{D} \cos \theta
\end{aligned}
$$

Where $C_{X}$ is the propulsion coefficient, $C_{Y}$ is transverse force coefficient, $C_{L}$ is lift coefficient, $C_{D}$ is the resistance coefficient.

\section{Current Situation of The Sail-Assisted}

Human beings have a long history of using wind energy. Sailing as ship propulsion device has a history of thousands of years. Restricted by some objective factors, the traditional sailing system couldn't solve the problem of the size and direction of the wind at that time, so the reliability of the ship navigation was poor. By the late 16th century, with the development of science and technology, the sailing boat had been replaced by the powered boat gradually. Nowadays, only some countries and regions of inland waterway and small scale fishing boat with the sailing system.

Using wind energy to be back on the agenda due to the energy crisis, rising oil prices and emissions control. At present, almost all ships are using fuel, fossil fuel is started for use on ship at the beginning of the 20th century, when the fuel bill accounted for only less than $10 \%$ of the operating costs, and nowadays the fuel fee in the operation of the ship cost ratio as high as $40 \%$ to $60 \%$. Oil cost issues and the environmental awareness drives people to seek alternative ways of shipping. Although wind can make the ship sailing reliability variation, but the oil crisis, environmental pollution, global warming and climate change show that wind energy development is not willing to, but the trend of the times, so more and more countries began to consider wind as auxiliary power.

According to their own marine environment and navigation condition, some countries began to study the Sail-Assisted from the start of the 20th century. Until now, they have made great achievements in this area, including Japan, Germany, the United States, Russia, France and Britain. Beyond that, some research work has been done in China and Indonesia.

Japan is one of the most advanced countries in this filed, it began to study the modem Sail-Assisted technology in 1970s. In 1980, Japan built the first Sail-Assisted ship with modern technology. This ship's displacement amount to 2400t, can carry a weight of $1600 t$, equipped with two folding fiber reinforced plastic sail and a low speed diesel engine as the auxiliary power, and they cooperate with each other. Compared with the ordinary motor ship which has the same displacement, this ship can save fuel 50\%. Until now, more than a dozen modern Sail-Assisted ships are operating in Japan.

Germany began to study the large Sail-Assisted ship in the 1960s. On December 15, 2007, "beluga Sky Sails" was launched in the port of Hamburg, Germany. It's the first watercraft with a huge kite provide part of the power in the world, and it operates by wind auxiliary engines, can reduce fuel consumption by $10 \%-35 \%$.The advantage of the kite is that it can use the most stable and strong wind from the upper air. Beluga which is the manufacturers of this ship has confirmed that it has received many orders from all over the world for the technology.

The United States is one of the earliest countries to study the Sail-Assisted technology. In 1970s, a special committee was formed to set up the planning of Sail-Assisted, and a series of trials are carried out in the tug, fishing boats, drilling ship and other various ship types which aimed at the traditional and modern Sail-Assisted technology. For example, they installed a triangular sail in "Atlantic", the displacement of which is 3100t. In the course of the experiment, they found that when the wind speed reached 6 , the ship can increase the speed of $1.5 \mathrm{kn}$, and can save fuel $20 \%$ than the ordinary motor ship. Through the research, the conclusion is that the common navigational ship sails can save fuel $20 \%-30 \%$.

In the field of Sail-Assisted technology, the main achievement of France is the development of the suction type turbine sail, the maximum lift coefficient is up to 5.5 to 6.0. "Alcyone" which is their test boat has experienced the test of crossing the Atlantic. According to the results of the test, the boat can get $60 \%-55 \%$ of the energy-saving effect under the condition of propagating along wind. 
The former Soviet Union has developed a series of rotor sail combinations. Its lift coefficient can up to 2.60 .

Britain developed the Walker sail type. This sail is a kind of wing, and it consists of a main wing plate and two auxiliary wing plates, their direction is automatically adjusted by a wind turbine and the thrust is 4 times higher than that of the common sail.

China has also made some achievements in the modern Sail-Assisted technology. Beginning in 1980s, Chinese developed a few small Sail-Assisted ship in the Yangtze River, has made gratifying progress in trial operation. In 1985, Wuhan Institute of Water Transportation Engineering developed $200 t$ arc wing Sail-Assisted ship launch, more than 50\% energy-saving effect. In the 90s of the 20th century, Ningbo Shipping Company developed a 2500 ton Sail-Assisted ship, the ship operated in January 1996, traveling from Japan to Ningbo.

\section{Application problems of Sail-Assisted technology}

Although the energy saving effect of Sail-Assisted has been recognized, but there are still many problems need to be carefully studied and resolved, such as the practical effect of Sail-Assisted, the relationship between energy saving and safety, sailing on the ship sailing performance problems, the influence of sailing on the ship's navigation performance, etc.

Balance problem between energy saving and navigation safety. Sail-Assisted ship can be divided into two forms: one is wind as the main thrust, diesel power plant as the auxiliary propulsion; the other is wind as auxiliary propulsion and diesel engine power plant as the main thrust. Obviously, the former can produce greater energy-saving effect, but its performance is greatly affected by the weather, and once in a hurricane, its security is inferior to the latter. Which form of the Sail-Assisted should be selected according to the specific circumstances to determine: for the former, it can be applied to the inland river or offshore in the monsoon but fewer hurricanes, and its route is relatively safe; Ocean going ships can use the latter. Therefore, in order to achieve optimal allocation of energy saving and navigation safety, we should to make research on the ship route and its weather conditions.

The matching problem of sail, engine and propeller. Sail thrust can form two energy-saving effects: one is to keep the speed constant, changes the output power of main engine; the other is to maintain the output power of the main engine, and change the speed. With the constant speed navigation, the change of the main engine load is random; the main engine power varies with the wind force and direction change, in other words, the main engine power varies with the size of auxiliary thrust which provided by the sails. Due to the instability of the wind speed, the size of the energy instability, in this case, in order to ensure the propeller to obtain the optimal propulsion efficiency, the best way is to use variable pitch propeller, and to achieve the best matching control of sail, engine and propeller. Therefore the matching characteristics of sail, engine and propeller of Sail-Assisted ship and its influence on the power plant, including the sail, the engine and the propeller, must be scientifically analyzed and demonstrated.

The problem of the sail type. The material of contemporary sails is different from that of the ancient, at present, the new material can make large sails, which can be controlled easily and conveniently, therefore, the modern Sail-Assisted ships can break through the traditional heavy and huge windsurfing equipment. From the perspective of the shape of the sail, there are square, triangular sail; from the perspective of the structure of the sail, there are hard and soft sail; from the perspective of the cross-section of the sail, there are laminar flow type, circular type and SY type etc. The problem is that which type of sails can produce a greater thrust and is suitable for modern ships.

The influence of ship navigation performance. After the installation of sailing, the ship's stability, yaw, main engine output power and other properties will be changed, the influence of heeling moment on ship's stability, floating condition and control ability needs to be studied. So, before installing sails, we must to analyze and calculate the performance to provide reliable performance analysis and economic basis for the ship installation sails. At the same time, before 
installing the auxiliary sails, we should consider the nature of the operations, the ship navigation area, departure period and other factors, and demonstrate their economy and feasibility.

Sailing control problem. When applying the sail to the auxiliary propulsion of a large ship, free retraction of sails must be considered. The sail should be open in good sea conditions, and ensure the course is the same as the wind direction. On the other hand, if we can't close the sail timely in bad weather, such as hurricanes, the ship will further increase danger of capsizing.

The choice of course. In order to obtain wind energy to accelerate the voyage of the ship, often need to change the course of the ship. In this case, the ship will deviate from the scheduled route, so that the ship will go a long distance, the diesel engine can be run longer, more fuel should be consumed, and the ship will also increase its sailing time. So we should study on optimization of wind energy and voyages.

In summary, the Sail-Assisted ship is better to sail on the course of a periodic Ocean monsoon. Scientific analysis of the global ocean climate and select the most beneficial route can make the application of Sail-Assisted ship to achieve the most ideal effect.

\section{Application prospect of the Sail-Assisted ship}

Although wind power may increase the uncertainty of the navigation, some shipping companies may not be willing to take such risks. However, the frequent occurrence of the oil crisis, the severe situation of global warming, serious pollution problems in recent years are warning us: humans can no longer use oil as the only reliable source of energy. The rising green energy will become the mainstream of the future global energy. The Sail-Assisted ship which can save energy and reduce pollution, will open a new era of science and technology of sailing.

\section{Reference:}

[1] Global Wind Report 2011. GWEC. (2011).

[2] Jianhai He, Yihuai Hu. Current Situation and Prospect of Wind Energy Application on Ship. SHIP ENGINEERING. No.5 (2013).

[3] Information on http://www.planetyacht.com/detail.Php?id=449.

[4] Information on http://www.marinebuzz.com.

[5] Thibaut Tincelin. EOSEAS Green Cruise Ship Concept. 7th Annual Green Ship Technology conference. (2010).

[6] Information on http://solarsailor.com/showroom/ solarsailor-trimaran-600-pax.

[7] Weiming Meng, Junhao Zhao, Lianzhong Huang. Application prospect of sail-assisted energy-saving ships. SHIP \& BOAT. No.5. (2009).

[8] Information on http:// www.starthrower.org/ products.htm. 